\title{
Inequalities in suicide mortality rates and the economic recession in the municipalities of Catalonia, Spain
}

\author{
Carme Saurina ${ }^{1,2^{*}}$, Manel Marzo ${ }^{1}$ and Marc Saez ${ }^{1,2}$
}

\begin{abstract}
Introduction: While previous research already exists on the impact of the current economic crisis and whether it leads to an increase in mortality by suicide, our objective in this paper is to determine if the increase in the suicide rate in Catalonia, Spain from 2010 onwards has been statistically significant and whether it is associated with rising unemployment.
\end{abstract}

Methods: We used hierarchical mixed models, separately considering the crude death rate of suicides for municipalities with more than and less than 10,000 inhabitants as dependent variables both unstratified and stratified according to gender and/or age group.

Results: In municipalities with 10,000 or more inhabitants there was an increase in the relative risk of suicide from 2009 onwards. This increase was only statistically significant for working-aged women (16-64 years). In municipalities with less than 10,000 inhabitants the relative risk showed a decreasing trend even after 2009. In no case did we find the unemployment rate to be associated (statistically significant) with the suicide rate.

Conclusions: The increase in the suicide rate from 2010 in Catalonia was not statistically significant as a whole, with the exception of working-aged women (16-64 years) living in municipalities with 10,000 or more inhabitants. We have not found this increase to be associated with rising unemployment in any of the cases. Future research into the effects of economic recessions on suicide mortality should take into account inequalities by age, sex and size of municipalities.

Keywords: Suicides rates, Economic recession, Unemployment rate, Hierarchical mixed models

\section{Introduction}

Considerable research has been carried out on the impact the current economic crisis has had on health [1-12]. It is well known that economic recessions have a negative impact on mental health disorders [13-17]. Moreover, this impact could be greater among the unemployed $[12,16]$.

Some of the studies analysing previous economic crises have found evidence of increased numbers of suicides [18-21] and some show a clear association between the increase in unemployment and the increase in the number of suicides $[18,19,22]$.

However, is there a clear causal relationship between the effects of the economic crisis and the number of

\footnotetext{
* Correspondence: carme.saurina@udg.edu

'Research Group on Statistics, Econometrics and Health (GRECS), University of Girona, Girona, Spain

${ }^{2}$ CIBER of Epidemiology and Public Health (CIBERESP), Madrid, Spain
}

suicides? Is the effect the same in all countries, and in all regions of a country [23, 24]? Exploring the impact of the current economic crisis in 54 countries, Chang et al. [23] showed that suicide rates are increasing both in Europe and America, and that they are higher among males and in countries with high levels of unemployment. In particular a $13.3 \%$ increase in the number of suicides in men was demonstrated in the European Union [23]. Spain ${ }^{1}$ in 2009 experienced a $7.2 \%$ increase in the suicide rate for males, but a slight decrease in females [25]. Karanikolos et al. [8] indicated that from 2007 suicides increased in countries such as Greece, Portugal and Spain. However, Ayuso-Mateos et al. [26], in response to Karanikolos et al. [8], pointed out that there was not an increase in Spain and Portugal, but rather a slight decrease in the number of suicides and that 
it was not possible to link increases in unemployment with the number of suicides.

Although previous research addresses the relationship between the increase in the number of suicides and the economic crisis, the evidence of the effects of the economic crisis on the number of suicides is still scarce. Exploring PubMed and Embase in April 2014, using the word 'suicide', combined with 'economic recession', 'economic crisis,' 'economic downturn' and 'financial crisis' and limiting the search to articles published in the last 5 years, provided a total of 131 references, 9 of which corresponded to 2014. Most correspond to revisions or proposals for future research. Only 29 of the articles provide quantitative evidence of the relationship between periods of economic crisis and suicide, and only 16 of those made any statistical inferences $[6,7,9,11,12,23-25,27-34]$.
The suicide (crude) rates in Catalonia follow a somewhat different temporal behaviour than that of the economic recession (Fig. 1). Crude rates for men fell from 2002 to 2007 (with a spike in 2004) and then started to rise (with a temporary decrease in 2009). For women, the peak in 2004 was less abrupt and the increase from 2010 was much sharper. Note also, that in the case of women the increase in suicide rates began in 2006, a year earlier than for men. At any rate, the changing trend in suicide rates for both men and women occurs well before the recession (two years beforehand for men and three for women).

In summary, while economic recessions clearly do have a negative impact on mental health, the evidence of the effects of the economic crisis on the number of suicides is still limited and consequently rising
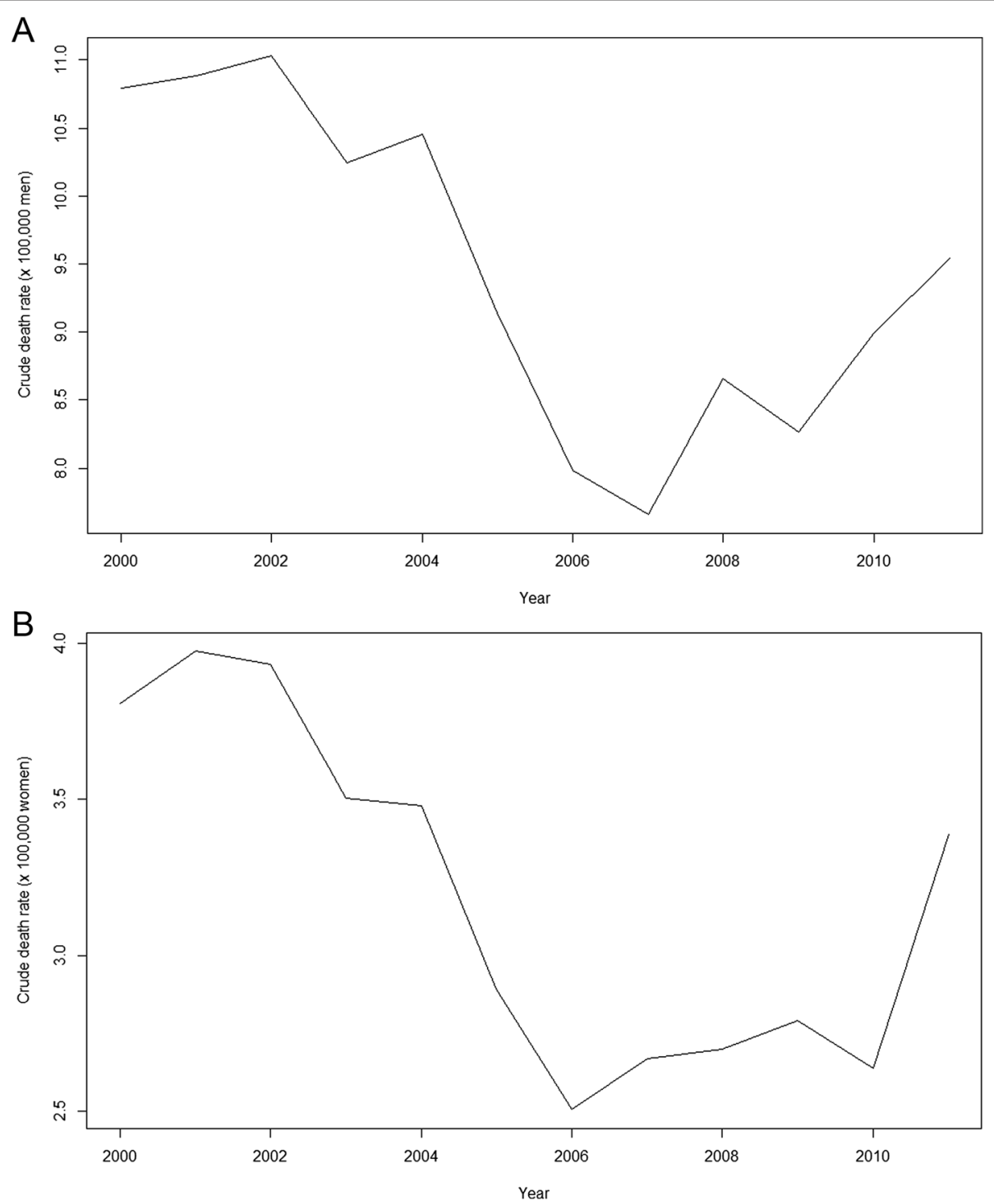

Fig. 1 Temporal evolution of crude rates of suicide (x 100.000 people). Catalonia, 2000-2011. a Men. b Women 
unemployment cannot be linked definitively to the number of suicides. Our objective in this paper is twofold. First, to establish if the increase in the suicide rate, especially since 2010 , is statistically significant and, second, to determine whether this increase has been associated with rising unemployment due to the economic crisis by analysing possible gender, age and size of municipalities differences.

\section{Methods}

\section{Setting}

The annual number of deaths in Catalonia, Spain, from 2000 to 2011 (for adults aged 16 years and over) by suicide and intentional self-harm (International Classification of Diseases (ICD-9 codes: E950-E959; ICD-10: X60-X84)) was provided by the Mortality Register of Catalonia.

\section{Studied municipalities}

For confidentiality reasons, data was only available for municipalities with 10,000 inhabitants or more (92 municipalities from a total of 946 municipalities in Catalonia). However, aggregated data was also available at comarca ${ }^{2}$ levels (a total of 44 comarcas in all Catalonia). In 2011, these 93 municipalities with 10,000 inhabitants or more comprised $77.33 \%$ of the population of Catalonia (i.e. $5,811,938$ of 7,501,853 inhabitants).

Using the information from the comarcas and from the municipalities of 10,000 inhabitants or more, we calculated for each comarca the number of suicides (total, by gender and by age group) in municipalities with less than 10,000 inhabitants. For instance, in the comarca of 'Alt Camp', there is only one municipality (Valls) with more than 10,000 inhabitants. We took the number of suicides among men for a given year in the comarca of 'Alt Camp' and subtracted the number of suicides among men in Valls $^{3}$ for the same year. We repeated this process for each year, sex and comarca. Note that, in this case we considered the number of suicides in all the municipalities, with less than 10,000 inhabitants, grouped together, unlike the municipalities with more than 10,000 inhabitants.

Population data as a total, by gender and according to age group for the 946 municipalities and the 44 comarcas from 2000 to 2011 was provided by the Statistical Institute of Catalonia (IDESCAT). IDESCAT also provided (for municipalities of 10,000 inhabitants or more and for the comarcas) the number of unemployed persons (registered in employment offices), the total number (population aged 16 to 65 ) and by gender, although in this case from 2005 to 2011. Again, we calculated these variables in each comarca for the other municipalities with less than 10,000 inhabitants (as mentioned in the previous paragraph).

Finally, for the municipalities of 10,000 inhabitants or more and for the remaining municipalities with less than
10,000 inhabitants, in each comarca we calculated both the crude death rates from suicide as well as the unemployment rates. Note that we used the population aged 16 to 65 as the denominator for unemployment rates instead of the active population, as the latter figure was not known.

The data provided included the total number of suicides, the number of suicides by gender (3902 men and 1343 women) and according to age group (16 to 64 years and 65 years or older).

\section{Statistical analysis}

We had, in fact, a mixed longitudinal design. Besides having two dimensions (time and municipality), this design allowed for the following points to be taken explicitly into account: i) we had units (municipalities in this case) that did not behave in the same way over time, ii) the effect of the explanatory variables on the response variable may not be the same for the different units, and iii) longitudinal observations within the same higherlevel unit (municipality in this case) are not independent of one another [24]. Furthermore, we wanted to explicitly allow for the estimation of municipality time trends and the effects of the economic crisis on suicides at the municipality level. For these reasons, we used hierarchical mixed models to assess the variation in suicide rates attributable to the economic crisis as well as the association between suicide rates and unemployment (further details can be found in Saurina et al. [24]). In both cases, we used the (crude death) rate of suicides as the dependent variable for municipalities with more than and less than 10,000 inhabitants separately, unstratified and stratified by gender (men and women) and according to age group (16-64 and 65 and older).

Following the example of Saurina et al. [24] in the models we included as explanatory variables, a time trend and a dummy variable for the crisis years 20092011. The dummy variable was designed to capture a break from past time trends. When assessing the association between unemployment and suicide, the unemployment rate was included instead of the dummy. In this case, a time trend was also included to monitor any spurious relationship, as suicides and unemployment could evolve over time in the same way.

Both the intercept and the coefficients associated with all of the explanatory variables were considered random effects. In other words, all coefficients were allowed to vary in the higher-level unit that was considered, i.e. municipalities (in the models of municipalities with more than 10,000 inhabitants) and comarca (in the models of municipalities with less than 10,000 inhabitants - areas hereinafter). In the case of the time trend, we assumed that the random effects vary by areas and year. Thus, we 


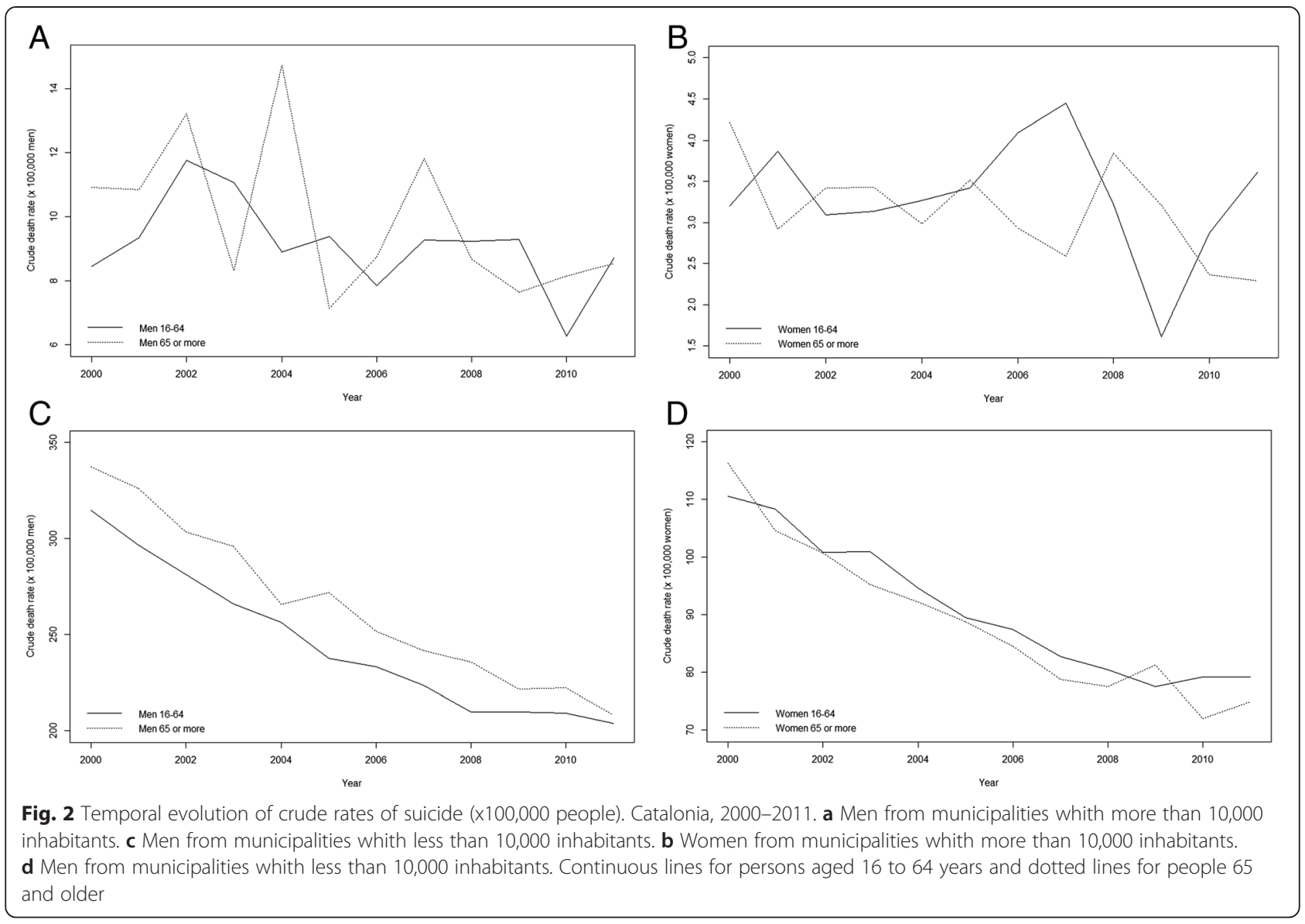

used a non-parametric approach to area trends, which we assumed to evolve non-linearly.

Heteroskedasticity, that is the consequence of heterogeneity between areas, was controlled through the random intercept (at the areas level), and autocorrelation, that is the serial dependence of the longitudinal observations within the same area, was controlled in all the models through an autoregressive model of order 1 .

In our case, the data contains numerous zero counts. In $77.2 \%$ of the municipalities of over 10,000 inhabitants and $85.2 \%$ of less than 10,000 inhabitants there was no suicide between 2000 and 2011. Typically, a Poisson model is assumed for modelling the distribution of the count observation or, at least, approximating its distribution. However, when there is an excess of zero counts, as in our case, the dispersion of the Poisson model underestimates the observed dispersion. Mixed-distribution models, such as the zero-inflated Poisson (ZIP), are often used in such cases. In particular, the zero-inflated Poisson distribution (ZIP) regression might be used to model count data for which the proportion of zero counts is greater than expected on the basis of the mean of the non-zero counts $[35,36]$. In this paper we used a Type 0 ZIP. Type 0 is a mixture of a truncated Poisson (the positive observations) and a point mass at 0 . This means, for instance, that Type 0 can have a lower probability at 0 than a pure Poisson.

The inferences were performed using a Bayesian approach, with the Integrated Nested Laplace Approximation (INLA) [37]. All analyses were conducted using the free software $\mathrm{R}$ (version 3.0.3), available through the INLA library.

\section{Results}

In municipalities with more than 10,000 inhabitants, as shown in Fig. 2a, the peak in 2004 of male suicide rates corresponded to the behaviour of the rates among men 65 years or older. This age group presented a drop from 2007 to 2009 that, probably, led to the interruption in 2009 of the increase in male suicide rates since 2007 (Fig. 1a). Furthermore, the increase from 2010 was greater in the case of men aged 16 to 64 years. An opposite temporal behaviour was observed in women between age groups 16-64 years and 65 and over (Fig. 2b). Thus, suicide rates for women aged 16 to 64 years increased from 2005 to peak in 2007 before falling from 2007 to 2009 and then once again increasing from 2009, albeit slightly less sharply from 2010 
Table 1 Estimation results from the models assessing the effects of the economic crisis on suicide death rates. Relative risks (95\% credibility interval)

\begin{tabular}{|c|c|c|c|}
\hline & \multicolumn{3}{|c|}{$\begin{array}{l}\text { Municipalities with } 10,000 \\
\text { inhabitants or more }\end{array}$} \\
\hline & 2009 & 2010 & 2011 \\
\hline All & $0.866(0.790,0.944)$ & $0.958(0.879,1.044)$ & $1.038(0.943,1.144)$ \\
\hline Men & $0.857(0.770,0.946)$ & $0.973(0.883,1.077)$ & $1.046(0.935,1.174)$ \\
\hline $16-64$ years & $0.881(0.783,0.978)$ & $0.972(0.875,1.084)$ & $1.036(0.914,1.183)$ \\
\hline$\geq 65$ years & $0.820(0.671,0.975)$ & $0.941(0.787 .1 .149)$ & $1.007(0.816$. 1.268) \\
\hline Women & $0.824(0.677,0.975)$ & $0.987(0.832 .1 .177)$ & $1.157(0.940,1.435)$ \\
\hline $16-64$ years & $0.833(0.649,1.030)$ & $1.049(0.844,1.322)$ & $1.261(0.958,1.676)$ \\
\hline \multirow[t]{3}{*}{$\geq 65$ years } & $0.987(0.895,1.020)$ & $0.989(0.902,1.028)$ & $0.991(0.905,1.039)$ \\
\hline & \multicolumn{3}{|c|}{$\begin{array}{l}\text { Municipalities with less than } \\
10,000 \text { inhabitants }\end{array}$} \\
\hline & 2009 & 2010 & 2011 \\
\hline All & $1.000(0.984$. 1.017) & 0.996 (0.977 . 1.013) & $0.992(0.968$. 1.012) \\
\hline Men & $0.998(0.980 .1 .014)$ & $0.994(0.973 .1 .011)$ & $0.991(0.965 .1 .011)$ \\
\hline $16-64$ years & $0.995(0.974$. 1.012) & $0.991(0.966 .1 .010)$ & 0.989 (0.959 . 1.011) \\
\hline$\geq 65$ years & $0.993(0.964$. 1.013) & $0.991(0.957 .1 .013)$ & $0.989(0.949 .1 .015)$ \\
\hline Women & $0.995(0.971$. 1.013) & $0.992(0.963 .1 .013)$ & $0.990(0.955 .1 .013)$ \\
\hline $16-64$ years & $0.993(0.964$. 1.013) & 0.991 (0.957 . 1.013) & 0.989 (0.949 . 1.015) \\
\hline$\geq 65$ & $0.993(0.964$. 1.013) & 0.991 (0.957 . 1.013) & 0.989 (0.949 . 1.015) \\
\hline
\end{tabular}

In bold, the $90 \%$ credibility interval did not contain the unit. In bold and shaded, the $95 \%$ credibility interval did not contain the unit

onwards. However, suicide rates among women aged 65 or older actually declined from 2005 until 2007, but then increased from 2007 to 2008 only to decline once again, although from 2010 onwards this decrease was smaller.

For municipalities with less than 10,000 inhabitants, although the rates were much higher than for municipalities with more than 10,000 inhabitants, their temporal behaviour was totally different (Fig. 2c and $2 \mathrm{~d}$ ) with a decrease from the beginning of the study period. Notice how, in this case, while the rates for men aged 65 years or more were always higher than those of men 16 to 64 years, the rates for women aged 65 or more were somewhat lower than those of women 16 to 64 years (albeit with some exceptions such as the peak of 2009).

The results of the estimation of the first model investigating the effect of the crisis on the excess number of suicides are shown in Table 1 . There was only a significant increase in the suicide rates for 2011 in municipalities with more than 10,000 inhabitants among women of all ages and, particularly, women aged 16 to 64 . Note, however, that it was only significant at $90 \%$. For other cases, although an increase in the suicide rates was observed in some cases, this was not statistically significant. For municipalities with less than 10,000 inhabitants no increase in the suicide rates was observed from 2009 onwards.
Figure 3 graphically shows the relative risks obtained. For municipalities with more than 10,000 inhabitants (Fig. 3a), relative risks showed a decreasing trend with a sharp drop for females from 2004 to 2006, and then increasing slightly until 2009. From 2009 onwards the increase in risk was higher. The behaviour in males was similar but with some minor differences. As with women, risk among men decreased until 2007 and then increased from 2009 onwards, but more steadily than in the case of women. Figure $3 \mathrm{~b}$ shows a decreasing trend in risk for both groups from 2006 in municipalities with less than 10,000 inhabitants. While there was a steady drop until 2006 for women, in the case of men there was a slight increase in risk up to 2006 before it then started to decline. In no case were results statistically significant. In Fig. 4, in which the evolution of the relative risk is shown only in the case of the population between 16 and 64, we can clearly see the largest increase in the relative risk for women since 2009.

The results obtained in the estimation of the second model, in which we investigated the possible relationship between unemployment and suicide, are shown in Table 2. The relative risks were not statistically significant in any case.

\section{Discussion}

In summary, we found that there was an increase, which was much greater in women, in the relative risks of 

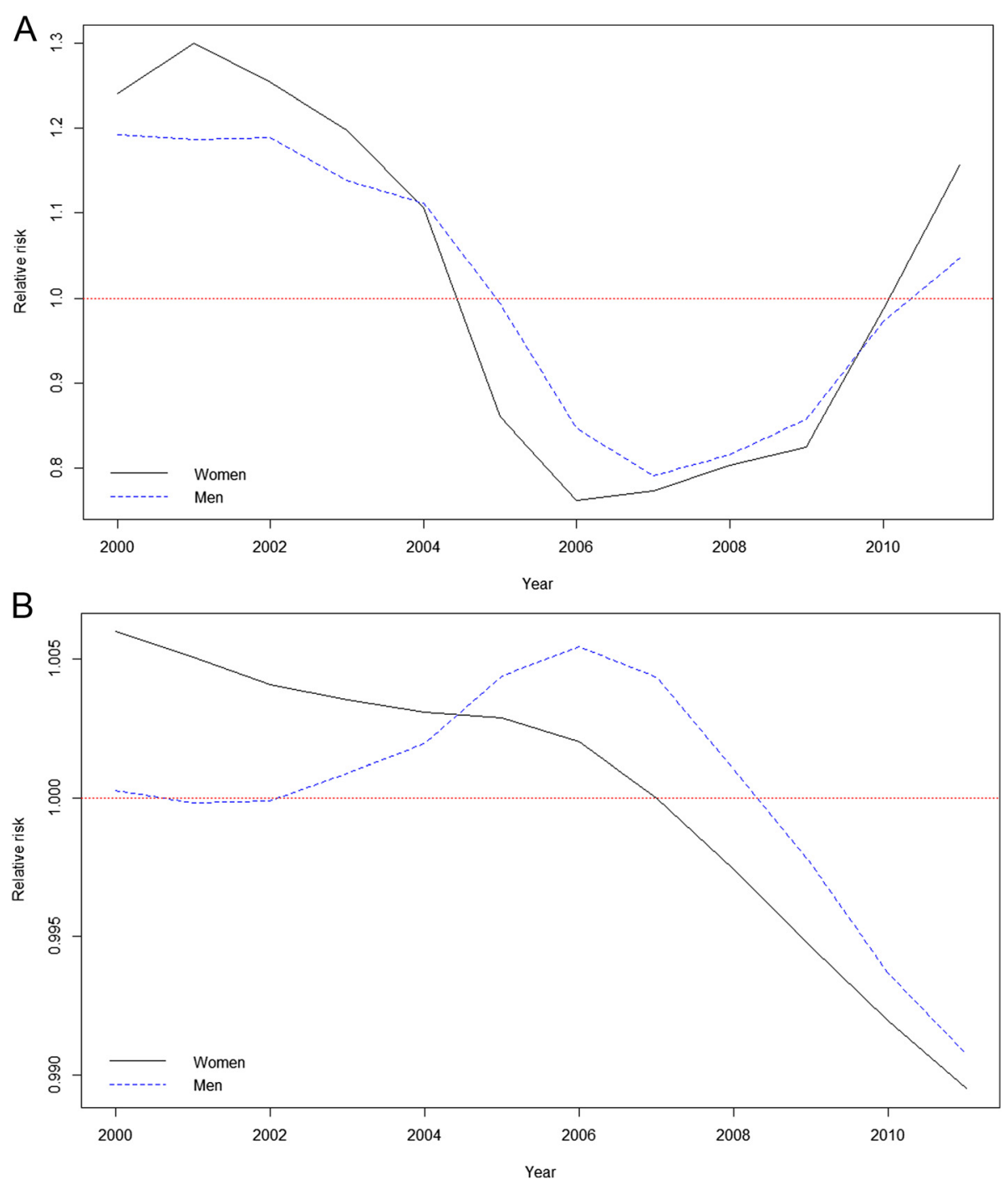

Fig. 3 Relative risk of suicide rates. a Municipalities whith 10,000 inhabitants or more. b Municipalities whith less than 10,000 inhabitants. Dotted lines for men and continuous lines for women

suicide from 2009 onwards. This increase was only found in municipalities with 10,000 or more inhabitants and was only statistically significant for working-age women (16-65 years), although marginally (at $90 \%$ of confidence). In municipalities with less than 10,000 inhabitants, however, relative risks showed a decreasing trend, even from 2009. Note that, because the number of suicides was grouped together, in this case rates were higher than in the case of municipalities with 10,000 inhabitants or more. In no case did we find the unemployment rate to be associated (statistically significant) with the suicide rate. This fact may bring into question a cause-effect relationship between the increase in suicides, from 2009, and the economic crisis, which in the case of Spain began precisely in 2009. In fact, as we mentioned earlier on, the changing trend in suicide rates actually occurs two to three years before 2009 .

There is little research that does not find a (statistically significant) association between the total rate of suicide and the economic crisis, as in our case [9, 10, 16, 26, 34]. As previously mentioned, Ayuso-Mateos et al. [26] noted that in Spain and Portugal there was no increase, as indicated by other studies [8, 11, 23], but instead a slight decrease in the number of suicides during the economic crisis. In fact, in three of the four studies referenced in this paper that focused on Spain [9, 16, 34], there is no significant increase in the number of suicides during the period of economic crisis (at least until 2011). Karanikolos et al. [38] replied to Ayuso-Mateos et al. [26], attributing the fact that no increase was 


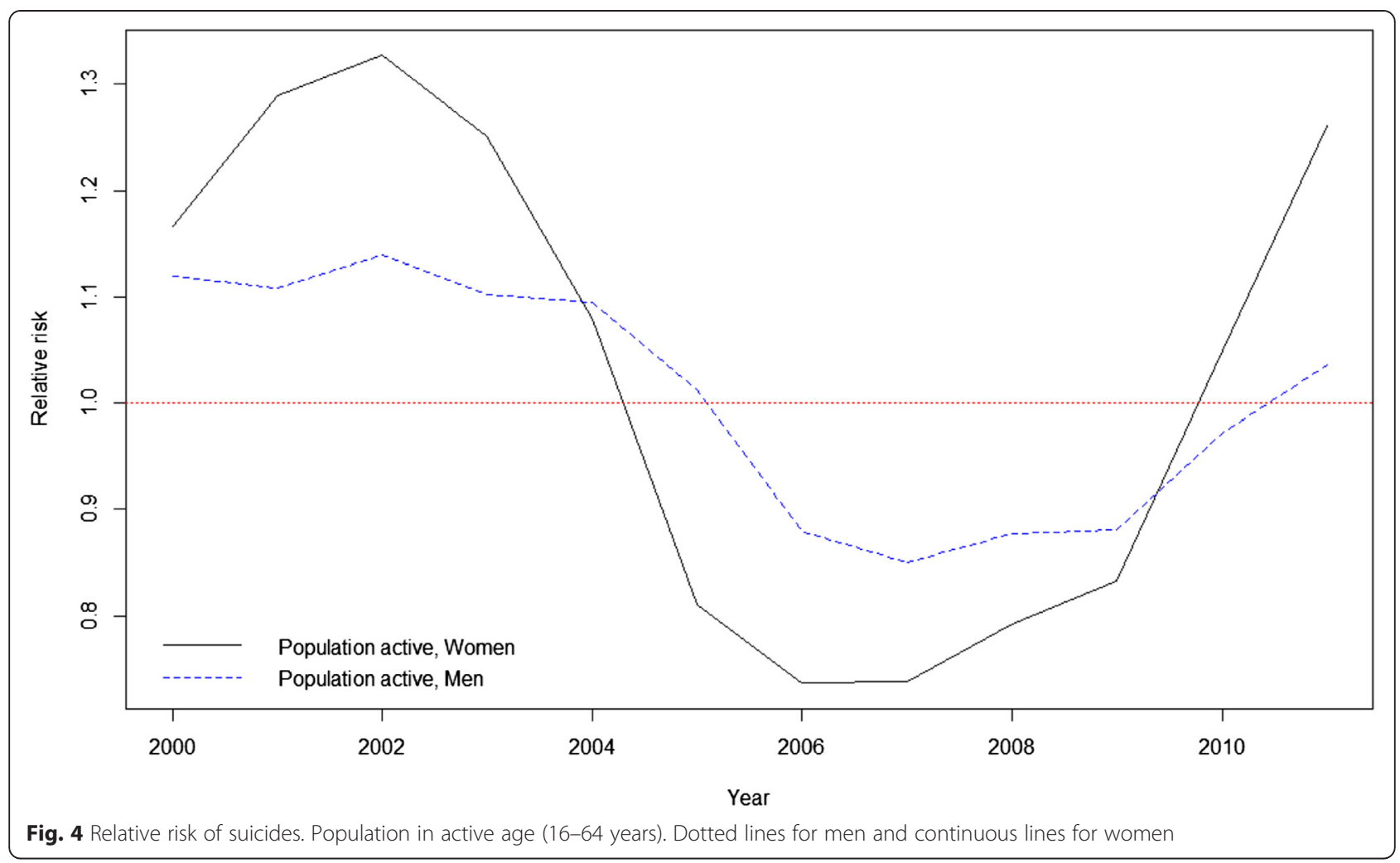

found to the total suicide rates, except inthe rates corresponding to men of working age who were most affected by the financial crisis. Furthermore, they point out that the suicides among Spanish people of working age increased by almost $10 \%$ above the underlying trend [25] (the fourth study focused specifically on Spain). Three important caveats should be noted in this case. First, López-Bernal et al. [25] estimated a 10 \% increase in suicide rates (above the underlying trend) for males (15 years and older) and including males 65 years and older. The increase was $10.4 \%$ for people (males and females, not only males) $15-39$ year old and $8.6 \%$ for $40-64$ year olds $\left(9.38 \%\right.$ for $15-64$ year olds $\left.{ }^{4}\right)$. Second, for the age groups 15-39 years and 40-64 years the estimated increases were not statistically significant $(p>0.1)$ (the estimated increase for males 15 years and older was statistically significant, $\mathrm{p}<0.05$ ). Third, if instead of considering the second quarter of 2008 as the beginning of the crisis in Spain and the standard definition of recession (a decline in the growth rate of GDP over two successive quarters) had been used, the results would have been very different (an even decrease in the overall rate, as evident from Fig. 1 in López-Bernal et al. [25]).

In our case, working-aged women (16-64 years), rather than men of that age group, experienced a statistically significant increase in relative risk of suicide during the economic crisis. Our findings are partly consistent with the results in Alameda-Palacios et al. [34] for Andalusia (Spain). Although they did not find significant differences between the change in annual rates before and during the economic crisis, 15 to 44 year old males did have an increased rate (equal to $1.21 \%$ per annum), while in women the rate increased both in the 15 to 44 year (equal to $0.93 \%$ ) range as well as 45 to 64 years (equal to $0.47 \%$ ). These regional differences were also found by Saurina et al. [24]. They indicate that there

Table 2 Estimation results from the models assessing the effects of unemployment on suicide death rates. Relative risks (95\% credibility interval)

\begin{tabular}{|c|c|c|c|c|}
\hline \multirow[b]{2}{*}{ All } & \multicolumn{2}{|c|}{ Municipalities with 10,000 inhabitants or more } & \multicolumn{2}{|c|}{ Municipalities with less than 10,000 inhabitants } \\
\hline & 0.826 & $(0.261,2.821)$ & 1.005 & $(0.619,1.647)$ \\
\hline Men & 1.823 & $(0.149,25.123)$ & 0.908 & $(0.540,1.554)$ \\
\hline $16-64$ & 0.668 & $(0.045,10.509)$ & 0.741 & $(0.436,1.285)$ \\
\hline Women & 1.095 & $(0.012,203.63)$ & 0.660 & $(0.323,1.369)$ \\
\hline $16-64$ & 0.062 & $(0.000,20.338)$ & 0.596 & $(0.278,1.307)$ \\
\hline
\end{tabular}


was no statistically significant increase in the number of suicides between 2008 and 2010 in England as a whole, but there were statistically significant increases and decreases in some regions. Catalonia, like Andalusia, is an autonomous Spanish community with its own specific characteristics in terms of customs, the character of its inhabitants, family relationships and its economic situation, meaning that any specific results would differ from those found for Andalusia or for Spain as a whole.

The decreasing trend in suicide relative risks in municipalities with less than 10,000 inhabitants could be attributed to the predominant rural feature of these municipalities. Saunderson et al. [39] in their study, although from a few years back, found that in England and Wales female suicides (standardised mortality rates) were highest in urban areas, whereas male suicides presented an excess in rural districts. They pointed out three factors that could explain such differences, namely the difference in suicide methods, the likelihood of communicating suicidal intent and, perhaps, variations in access to psychiatric services [39]. Much more recently, Qin [40] pointed out that poverty, one possible cause of suicide, is an urban phenomenon. According to Qin, living in a more urbanized area reduces the risk of suicide significantly among men, whereas it increases the suicide risk among women [40]. However, neither Saunderson et al. [39] nor Qin [40] explain why this phenomenon occurs mostly among women. In fact, before the crisis the Commission of the European Communities warned that urban areas were the scene of multiple forms of discrimination [41], regardless of gender issues. Severe poverty is more prevalent in urban settings as the urban poor are poorer than the poor living in rural areas. Urban poverty is more prevalent among young adults with higher rates of school failure and thus, reduced access to the labour market. Such poverty leads to marginality, especially when coupled with increased drug and alcohol use [42]. In our case, while we have also found that suicide is an urban phenomenon and rising among women, we are reluctant to attempt to provide an explanation for this phenomenon. What is clear, however, is that further research into not only this rise in the suicide rate among women, but also the causes of it, is required and would have implications on health equity.

Moreover, there are many studies showing that poverty does not affect both sexes equally. Women face a higher risk of poverty and generally have greater difficulties in overcoming the situation [43]. The feminization of poverty is usually explained by the difficult reconciliation of work and family life, by the increased presence of women heading single-parent households and the lack of social protection, among other causes [44, 45].

This paper could present some limitations. First, although we work with official data and therefore it is validated data, there could be an under-registration in the number of suicides. If this were the case, we would have underestimated the effect of the economic crisis on the evolution of suicide rates. Second, we work with aggregated data and, apart from the known ecological fallacy; we have not been able to control all possible confounding. Third, the recession in Catalonia (in fact throughout Spain) continued into 2014 and the effects of the crisis continue to be felt today. However, suicide mortality data are not available beyond 2011. The unavailability of such data from 2012-2014, therefore, could be a major constraint. Nevertheless, in Catalonia the crisis actually worsened from April 2010 (coinciding with the introduction of restrictive policies by the Spanish government). In this sense, in this article we have been able to capture this fact. Again, for reasons of data availability, the denominator used for the computation of unemployment rates did not coincide with the active population. However, the active population practically coincides with the population between 16 and 65 years old. Finally, it is not easy to associate urbanity or rurality to municipalities when guided only by size.

\section{Conclusions}

Our first objective in this paper was to ascertain if the increase in the suicide rates in Catalonia, especially since 2010, was statistically significant. While we have shown that the increase in the suicide rate from 2010 in Catalonia was not statistically significant as a whole, it was statistically significant for working-age women (16-64 years) living in municipalities with 10.000 or more inhabitants.

The second objective was to determine if this increase is associated or not with rising unemployment as a result of the economic crisis. Our work rejects this association in all cases and the study suggests that future research into the effects of economic recessions on suicide mortality should take into account inequalities by age, sex and size of municipalities.

As a final conclusion, we believe we have provided evidence that the increase in suicides since the onset of the Great Recession cannot be entirely attributed to it. Undoubtedly, there is a link between poverty and mental health, which in extreme cases may end in suicide. But why it is more prevalent among women and in urban areas are aspects that should not only be considered in health policy, but certainly deserve further research work as well.

\section{Endnotes}

${ }^{1}$ The Spanish economy went into recession in the first quarter of 2009 after the GDP fell for two consecutive quarters. Although the Spanish economy emerged from this first recession in the first quarter of 2010, when GDP showed positive growth rates, it slipped 
back into recession in the last quarter of 2011 (double dip) and did not move out of recession until the third quarter of 2013.

${ }^{2} \mathrm{~A}$ comarca can be considered equivalent to a county.

${ }^{3}$ If there were more than one municipality with 10,000 inhabitants or more, we subtracted the number of suicides of all these municipalities.

${ }^{4}$ Using a weighted average calculated using Tables 1 and 2 in Lopez-Bernal et al. [25].

\section{Competing interests}

There are no conflicts of interest for any of the authors. All authors disclose any actual or potential conflict of interest including any financial, personal or other relationships with other people or organisations within three years of beginning the submitted work that could inappropriately influence, or be perceived to influence, their work.

\section{Authors' contributions}

CS and MS have the idea of the paper. CS carries out the bibliografical research, writes the introduction, collaborates in the statistical analysis and in the writing of results and conclusions. MS carries out the statistical analysis, did the figures, writes the methods, and collaborates in the writing of the results and conclusions. MM obtains the data and did the tables. All authors read and approved the final manuscript.

\section{Acknowledgements}

This work was partly funded by the CIBER of Epidemiology and Public Health (CIBERESP), through the strategic subprogram 'Crisis and Health' and by the project 'Compositional and Spatial Analysis' (COSDA), 2014SGR551, AGAUR, Catalan Government. We appreciate the comments of the two anonymous reviewers who, without doubt, have helped us to improve our work.

Received: 19 January 2015 Accepted: 17 July 2015

\section{Published online: 08 September 2015}

\section{References}

1. Simou E, Koutsogeorgou E. Effects of the economic crisis on health and healthcare in Greece in the literature from 2009 to 2013: A systematic review. Health Policy. 2014;115(2-3):111-9.

2. Stuckler D, Basu S, Suhrcke M, McKee M. The health implications of financial crisis: a review of the evidence. Ulster Med J. 2009;78(3):142-5.

3. Falagas ME, Vouloumanou EK, Mavros MN, Karageorgopoulos DE. Economic crises and mortality: a review of the literature. Int J Clin Pract. 2009;63(8):1128-35.

4. Kentikelenis A, Karanikolos M, Papanicolas I, Basu S, McKee M, Stuckler D. Health effects of financial crisis: omens of a Greek tragedy. Lancet. 2011;378:1457-8.

5. Suhrcke M, Stuckler D, Suk JE, Desai M, Senek M, McKee M, et al. The impact of economic crises on communicable disease transmission and control: a systematic review of the evidence. PLoS One. 2011;6(6):e20724.

6. Stuckler D, Basu S, Suhrcke M, Coutts A, McKee M. Effects of the 2008 recession on health: a first look at European data. Lancet. 2011;378:124-5.

7. Nandi A, Charters TJ, Strumpf EC, Heyman J, Harper S. Economic conditions and health behaviours during the 'Great Recession'. J Epidemiol Community Health. 2013;67:1038-46.

8. Karanikolos M, Mladovsky P, Cylus J, Thomson S, Basu S, Stuckler $D$, et al. Financial crisis, austerity, and health in Europe. Lancet. 2013;381(9874):1323-31. Lancet, 2013;382(9820):392.

9. Regidor E, Barrio G, Bravo MJ, de la Fuente L. Has health in Spain been declining since the economic crisis? J Epidemiol Community Health. 2014;68:280-2

10. Mattei G, Ferrari S, Pingani L, Rigatelli M. Short-term effects of the 2008 Great Recession on the health of the Italian population: an ecological study. Soc Psychiatry Psychiatr Epidemiol. 2014 (In press). DOI:10.1007/s00127-014-0818-z.

11. Baumbach A, Gulis G. Impact of financial crisis on selected health outcomes in Europe. Eur J Public Health. 2014 (In press). DOI: 10.1093/eurpub/cku042.

12. Urbanos-Garrido RM, Lopez-Valcarcel BG. The influence of the economic crisis on the association between unemployment and health: an empirical analysis for Spain. Eur J Health Econ. 2014 (In press). DOI: 10.1007/s10198-014-0563-y.

13. Uutela A. Economic crisis and mental Health. Curr Opin Psychiatry 2010;23(2):127-30.

14. Zivin K, Paczkowski M, Galea S. Economic downturns and population mental health: research findings, gaps, challenges and priorities. Psychol Med. 2011;41(7):1343-8.

15. Mclnerney M, Mellor JM, Nicholas LH. Recession depression: Mental health effects of the 2008 stock market crash. J Health Econ. 2013;32(6):1090-104.

16. Gili M, García-Campayo J, Roca M. Economic crisis and mental health. SESPAS Report 2014 [in Spanish]. Gac Sanit. 2014;28(suppl 1):104-108.

17. McKenzie SK, Imlach Gunasekara F, Richardson K, Carter K. Do changes in socioeconomic factors lead to changes in mental health? Findings from three waves of a population based panel study. J Epidemiol Community Health. 2014;68(3):253-60.

18. Morrell S, Taylor R, Quine S, Kerr C. Suicide and unemployment in Australia 1907-1990. Soc Sci Med. 1993;36:749-56.

19. Gavrilova NS, Semyonova GN, Gavrilov LA. The response of violent mortality to economic crisis in Russia. Popul Rev Policy Rev. 2000;19:397-419.

20. Chang SS, Gunnell D, Sterne JA, Lu TH, Cheng AT. Was the economic crisis 1997-1998 responsible for rising suicide rates in East/Southeast Asia? A time-trend analysis for Japan, Hong Kong, South Korea, Taiwan, Singapore and Thailand. Soc Sci Med. 2009;68:1322-31.

21. Luo F, Curtis FS, Quispe-Agnoli M, Ouvang L, Crosby AE. Impact of business cycles on US suicide rates, 1928-2007. Am J Public Health. 2011;101:1139-46

22. Yip PS, Caine ED. Employment status and suicide: the complex relationships between changing unemployment rates and death rates. J Epidemiol Community Health. 2011;65:733-6.

23. Chang SS, Stuckler D, Yip P, Gunnell D. Impact of 2008 global economic crisis on suicide: time trend study in 54 countries. BMJ. 2013;347:f5239.

24. Saurina C, Bragulat B, Saez M, López-Casasnovas G. A conditional model for estimating the increase in suicides associated with the 2008-2010 economic recession in England. J Epidemiol Community Health. 2013;67(9):779-87.

25. López-Bernal JA, Gasparrini A, Artundo CM, McKee M. The effect of the late 2000s financial crisis on suicides in Spain: an interrupted time-series analysis. Eur J Public Health. 2013;23(5):732-6.

26. Ayuso-Mateos JL, Pita-Barros P, Gusmão R. Financial crisis, austerity, and health in Europe. [Comment to: Karanikolos et al. Lancet. 2013; 381(9874):1323-1331]. Lancet. 2013;382:391-2.

27. Thomas K, Chang SS, Gunnell D. Suicide epidemics: the impact of newly emerging methods on overall suicide rates - a time trends study. BMC Public Health. 2011;11:314.

28. Barr B, Taylor-Robinson D, Scott-Samuel A, McKee M, Stuckler D. Suicides associated with the 2008-10 economic recession in England: time trend analysis. BMJ. 2012;345:e5142

29. Yoon JH, Junger W, Kim BW, Kim YL, Kosh SB. Investigating the time lag effect between economic recession and suicide rates in agriculture, fisheries, and forestry workers in Korea. Saf Health Work. 2012;3:294-7.

30. Garcy AM, Vågerö D. Unemployment and suicide during and after a deep recession: a longitudinal study of 3.4 million Swedish men and women. Am J Public Health. 2013;103(6):1031-8.

31. Kontaxakis V, Papaslanis T, Havaki-Kontaxaki B, Tsouvelas G, Giotakos O, Papadimitriou GN. Suicide in Greece: 2001-2011. Psychiatrike. 2013;24(3):170-4.

32. Chan CH, Caine ED, You S, Fu KW, Chang SS, Yip PS. Suicide rates among working-age adults in South Korea before and after the 2008 economic crisis. J Epidemiol Community Health. 2014;68(3):246-52.

33. Pompili M, Vichi M, Innamorati M, Lester D, Yang B, De Leo D, Girardi $P$. Suicide in Italy during a time of economic recession: some recent data related to age and gender based on a nationwide register study. Health Soc Care Community. 2013 DOl:10.1111/hsc.12086.

34. Alameda-Palacios J, Ruiz-Ramos M, García-Robredo B. Suicide, antidepressant prescription and unemployment in Andalusia (Spain) [in Spanish]. Gac Sanit. 2014 (In press). DOl:10.1016/j.gaceta.2013.12.005.

35. Breslow NE. Extra-Poisson variation in log-linear models. Appl Stat. 1984;33:38-44.

36. Broek J. A score test for zero inflation in a Poisson distribution. Biometrics. 1995;51:731-43.

37. Rue H, Martino S, Chopin N. Approximate Bayesian inference for latent Gaussian models by using integrated nested Laplace approximations 
(with discussion). J R Stat Soc Ser B. 2009;71:319-92. available in: http://www.math.ntnu.no/ hrue/r-inla.org/papers/inla-rss.pdf, last accessed on March 30, 2014.

38. Karanikolos M, Mladovsky P, Cylus J, Thomson S, Basu S, Stuckler D, et al. Financial crisis, austerity, and health in Europe. [Authors' reply]. Lancet. 2013;382(9890):392.

39. Saunderson T, Haynes R, Langford $\Perp H$. Urban-rural variations in suicides and undetermined deaths in England and Wales. J Public Health Med. 1998;20:261-7

40. Qin P. Suicide risk in relation to level of urbanicity - a population-based linkage study. Int J Epidemiol. 2005;34(4):846-52.

41. Commission of the European Communities. Framework for Action for Sustainable Urban Development in the European Union. Brussels: Communication from the Commission of the European Communities (COM), 605 final; 1998. p. 17.

42. Renes V. Social dimension of poverty and social intervention [in Spanish]. Documentación Social. 2000;119:259-274.

43. Ayllón S. Poverty dynamics in Catalonia: a first approximation [in Catalan]. Quaderns d'Acció Social i Ciutadania. 2009;5:30-2.

44. Ayllón S, Mercader M, Ramos X. Characterization of deprivation and poverty in Catalonia. J Appl Econ. 2007;44:137-75.

45. Brunet I, Valls F, Belzunegui N. Female poverty: hidden poverty? An analysis of the risk of poverty by gender in different stages of life. J Int Org. 2009;3:91-110.

\section{Submit your next manuscript to BioMed Central and take full advantage of:}

- Convenient online submission

- Thorough peer review

- No space constraints or color figure charges

- Immediate publication on acceptance

- Inclusion in PubMed, CAS, Scopus and Google Scholar

- Research which is freely available for redistribution 